\title{
Attention and the subjective expansion of time
}

\author{
PETER ULRIC TSE \\ Dartmouth College, Hanover, New Hampshire \\ JAMES INTRILIGATOR \\ University of Wales, Bangor, Wales \\ JOSÉE RIVEST \\ York University, Toronto, Ontario, Canada \\ and \\ PATRICK CAVANAGH \\ Harvard University, Cambridge, Massachusetts
}

\begin{abstract}
During brief, dangerous events, such as car accidents and robberies, many people report that events seem to pass in slow motion, as if time had slowed down. We have measured a similar, although less dramatic, effect in response to unexpected, nonthreatening events. We attribute the subjective expansion of time to the engagement of attention and its influence on the amount of perceptual information processed. We term the effect time's subjective expansion (TSE) and examine here the objective temporal dynamics of these distortions. When a series of stimuli are shown in succession, the lowprobability oddball stimulus in the series tends to last subjectively longer than the high-probability stimulus even when they last the same objective duration. In particular, (1) there is a latency of at least $120 \mathrm{msec}$ between stimulus onset and the onset of TSE, which may be preceded by subjective temporal contraction; (2) there is a peak in TSE at which subjective time is particularly distorted at a latency of $225 \mathrm{msec}$ after stimulus onset; and (3) the temporal dynamics of TSE are approximately the same in the visual and the auditory domains. Two control experiments (in which the methods of magnitude estimation and stimulus reproduction were used) replicated the temporal dynamics of TSE revealed by the method of constant stimuli, although the initial peak was not apparent with these methods. In addition, a third, control experiment (in which the method of single stimuli was used) showed that TSE in the visual domain can occur because of semantic novelty, rather than image novelty per se. Overall, the results support the view that attentional orienting underlies distortions in perceived duration.
\end{abstract}

The perception of duration is rooted in the perceptual processing of events. In cases of prospective duration judgments (i.e., when observers know that the experiment is about judging durations), when no concurrent processing of stimuli is required of observers, the ratio of judged duration to real duration generally increases as a function of both the number of stimuli that occur over an interval (e.g., Fraisse, 1963; Frankenhauser, 1959; Ornstein, 1969; Thomas \& Brown, 1974) and the complexity of those stimuli (e.g., Avant, Lyman, \& Antes, 1975; Schiffman \& Bobko, 1974; Thomas \& Weaver, 1975).

This research was supported by McDonnell-Pew Grant 98-49CNS and NIH Grant R03 MH0609660-01 to P.U.T., by the Max Planck Society, AASERT Grant F49620-94-1-0376 to P.C., and by NSERC Grant 015593 to J.R. We thank Scott Brown and Peter Killeen for their constructive comments as reviewers. Correspondence concerning this article should be addressed to P. U. Tse, Department of Psychological and Brain Sciences, Dartmouth College, Moore Hall, Hanover, NH 03755 (e-mail: peter.tse@dartmouth.edu).

Note-This article was accepted by the previous editorial team, headed by Neil Macmillan.
However, when observers must process nondurational information about stimuli during prospective tasks or when they must perform a concurrent task, the ratio of judged to real time generally decreases as a function of the amount of information processed (e.g., Grondin \& Macar, 1992; Hicks \& Brundige, 1974; Hicks, Miller, \& Kinsbourne, 1976; Hülser, 1924; Katz, 1906; Macar, Grondin, \& Casini, 1994; Predebon, 1996; Quasebarth, 1924; Thomas \& Cantor, 1978; Underwood \& Swain, 1973; Zakay, 1993; Zakay \& Tsal, 1989). Duration estimations therefore follow opposite trends in prospective experiments that involve concurrent processing and those that do not. In the absence of concurrent processing, subjective time expands, whereas in its presence, it typically contracts. We henceforth will refer to the subjective expansion of perceived duration as time's subjective expansion (TSE). Our goal here is to determine the temporal dynamics of TSE and to determine the role of attention in this illusion.

An extensive literature provides evidence for the hypothesis that attention plays a role in the perception of duration (e.g., James, 1890/1950; Katz, 1906; Mattes \& Ulrich, 1998). Building on earlier models (Creelman, 
1962; Treisman, 1963), Thomas (Cantor \& Thomas, 1977; Thomas \& Brown, 1974; Thomas \& Cantor, 1978; Thomas \& Weaver, 1975) and Hicks (Hicks, Miller, Gaes, \& Bierman, 1977; Hicks et al., 1976) have proposed an attentional allocation/distraction model, according to which attention can increase (or decrease) the perceived duration of a unit of objective time. If attention is distracted by nontemporal information processing, less capacity is available for processing temporal information (Kahneman, 1973), and duration judgments will tend to decrease or become less reliable (Brown, 1985). If attention is not distracted from temporal information processing, more capacity is available for processing temporal information, and duration judgments will tend to increase. In agreement with Fraisse (1963), these authors argue that the prospective judgment of time requires attention to the passage of time. Concurrent processing entails a relative underestimation of clock time, because the observer must attend to the distracting task, rather than to the passage of time as such. When not paying attention to cues for the passage of time, the observer misses more such cues, causing underestimations of clock time. Fraisse (1984) found evidence supporting this model (Cantor \& Thomas, 1977; Thomas \& Cantor, 1978). In particular, the easier a concurrent task is, the more observers tend to overestimate an interval, presumably because when a distracting task is easy, observers are able to attend more to duration.

According to these models, there is a counter that keeps track of the number of units ${ }^{1}$ of temporal information processed for a given perceived event (Thomas \& Weaver, 1975; Treisman, 1963). These models argue that the number of units of temporal information that are counted decreases when attention is distracted from processing the duration of an interval. According to these models, attention increases duration judgments when duration per se is attended, because fewer temporal cues are missed. However, the data described here suggest that it is also possible that the number of units of temporal information processed is boosted above baseline when an observer orients to an improbable event. If attending to a stimulus boosts information processing of that stimulus, the counter would count more units, and subjective time would expand. The missed temporal cues and attentional boost interpretations are not mutually exclusive. Both could contribute to distortions in perceived duration, and both are compatible with the notion of a counter or some other mechanism that measures the amount of information processed in order to calculate the duration of perceived events.

\section{Aims of the Present Study}

In this series of experiments, the role of attentional orienting in the subjective expansion of time was explored by testing both visual and auditory stimuli within an oddball paradigm. In an oddball paradigm, the observer responds to a low-probability stimulus that occurs within a train of high-probability stimuli. We decided to use an oddball paradigm because a large literature has shown that detection of an oddball typically leads to marked changes in event-related potentials that are believed by many researchers to be related to attentional mechanisms (e.g., Garcia-Larrea, Lukaszewicz, \& Mauguiere, 1992; Polich, 1986; Potts, Liotti, Tucker, \& Posner, 1996). Moreover, it is believed that a transient or exogenous component of attention is allocated automatically to the abrupt onset of a new stimulus (e.g., Nakayama \& Mackeben, 1989; Remington, Johnston, \& Yantis, 1992). Since observers tend to orient and, thus, attend to an oddball quite automatically, an oddball paradigm may offer certain advantages over experimental paradigms that manipulate willed, sustained, or endogenous attention to stimuli. In particular, since the present research focused on the temporal dynamics of TSE, an oddball paradigm afforded us good control over the timing of observers' allocation of attention.

The majority of research in the time literature supports a model according to which paying more (less) attention to the duration of an event increases (decreases) its perceived duration. Questions remain, however. Is the expansion in perceived duration really an attentional effect, or is it simply a consequence of the amount of information processed? If attention increases the amount of information processing brought to bear on a stimulus, it might be difficult to separate these two possibilities. However, a strictly attentional account would make at least four predictions that a (nonattentional) speeded information-processing account would not. First, at least $120-150 \mathrm{msec}$ are required before attention can be allocated to a new stimulus (e.g., Hikosaka, Miyauchi, \& Shimojo, 1993; Nakayama \& Mackeben, 1989). If it can be shown that there is an expansion of perceived durations for objective durations above $\sim 120 \mathrm{msec}$, but none for objective durations below this, this would support an attentional account. Second, attention is commonly believed to have two components, one transient (or exogenous) and one sustained (or endogenous; e.g., Nakayama $\&$ Mackeben, 1989). These two attentional components have different temporal dynamics, and this difference should manifest itself in the TSE data. Third, attention is a central process and should, therefore, exert its effects in the visual and the auditory modalities in a similar fashion. Lastly, there is extensive evidence that attention cannot be applied to the image itself. Rather, attention can be allocated only over information that has been processed by grouping, shape formation, and other processes that operate preattentively (e.g., Baylis \& Driver, 1995; He \& Nakayama, 1992; Rensink \& Enns, 1995). TSE should, therefore, not be a function of image novelty per se but, instead, should be a function of the novelty of preattentively processed information.

In our experiments, we used four psychophysical methods to assess prospective time judgments: the method of constant stimuli, the method of magnitude estimation, the method of stimulus duration reproduction, and the method of single stimuli. We first (Experiments 1-4) 
used the precise but time-consuming method of constant stimuli to obtain measures of the amount of subjective temporal distortion for many stimulus conditions. We then used other, "rougher" methods as controls (Experiments 5-7) to verify whether the temporal dynamics of TSE revealed by the first method were reliable. It is known that the method of measurement can influence temporal judgments (Allan, 1979; Zakay, 1993). However, if the underlying effect is robust, it should manifest itself regardless of the method used to probe it.

Our goal is to describe the objective temporal dynamics of distortions in subjective time. We have limited the present research to the 75- to 4,000-msec range, because longer durations most likely involve memory processes beyond those of short-term memory. Some researchers have called the amount of experience sustainable within a short-term memory store the psychological present (Fraisse, 1963; Michon, 1978) and have argued that it has an upper limit of $5 \mathrm{sec}$ and an average value of $2-3 \mathrm{sec}$ (Fraisse, 1984). We have limited our research to an examination of distortions in this time range. We have done this in order to study distortions of subjective time as such, rather than the long-term memory properties of temporal experience.

\section{EXPERIMENT 1A TSE for an Expanding Oddball}

In Experiment 1A, we determined how long in objective duration an expanding oddball would have to be in order to have the same subjective duration as stationary standards. We placed an oddball event of variable clock duration in a temporal sequence of standards, each of which lasted $1,050 \mathrm{msec}$. The observers' task was to say whether the expanding ball lasted longer than or not as long as the standards.

\section{Method}

Observers. The observers were 3 psychophysicists from Harvard's vision lab and 1 student (C.T.). Two were authors (P.T. and J.I.), and 2 were naive with respect to the purpose of the experiment. All had normal or corrected-to-normal vision.

Stimuli and Apparatus. The stimuli were presented using an Apple Power Macintosh computer on an Apple 13-in. color monitor with a refresh cycle of $15 \mathrm{msec}$. Timing was strictly controlled by linking the duration of stimulus presentation to a counter of screen refreshes. The standard was a black circle with a constant 363.6-arcmin radius, centered on the screen. An expanding black disk with an initial radius of 63.6 arcmin $\left(1.06^{\circ} ; 30\right.$ pixels $)$ and a final radius of 211.7 arcmin $\left(3.53^{\circ} ; 100\right.$ pixels $)$, centered on the screen, was used as the oddball. To ensure precise control of timing, all moving stimuli were created using look-up table animation. Both standard and oddball stimuli were presented on a white background of approximately $60 \mathrm{~cd} / \mathrm{m}^{2}$.

Procedure. The observers sat $57 \mathrm{~cm}$ from the screen. They were required to fixate the center of each standard or oddball as it appeared and to maintain fixation on this location (screen center) between the appearance of successive stimuli throughout the experiment. No fixation point was used, because this tended to create a distracting impression of apparent motion when stimuli appeared.
Each oddball occurred within a train of standard stimuli of constant objective duration $(1,050 \mathrm{msec})$. In order to obtain a psychometric function, the expanding oddball was presented at 9 objective durations around a central duration. The sequence of oddball durations tested within an experiment was randomized. The central duration was obtained by testing 13 objective durations over a wide range on two of the experimenters and using the average point of subjective equality (PSE) obtained as the central duration for all other observers. The oddball appeared six times at each of the 9 test durations. Durations were obtained by testing at equal intervals of, for example, $75 \mathrm{msec}$ from the presumed PSE in both the upward and the downward directions. The 9 durations tested were 450, 525, $600,675,750,825,900,975$, and $1,050 \mathrm{msec}$. So that the observers could not know when the oddball would appear, from 7 to 12 standards would appear between 2 oddballs. On average, oddballs were separated by the successive appearance of approximately 10 standard disks, so that a typical experiment consisted of approximately 600 stimuli presented in succession (54 oddballs intermixed with the 540 standards). The observers were told that all the standards were of constant duration. The observers were told to leave their left hand on the button for "shorter" and their right hand on the button for "longer." Following the appearance of any oddball, the observers responded "longer" if the oddball appeared to last longer than the standards and "shorter" if it appeared not to last as long as the standards. The observers had to press one of these two buttons before the appearance of the third standard after offset of the oddball. This allowed the observers to confirm their decision that the oddball felt longer or less long than the standards. If the observers failed to respond before the appearance of the third standard after the oddball, their answer, if any, was not recorded. Standards were available both before and after oddball presentation, and the observers were encouraged to use both of these standards in making their judgment of duration relative to the standard. All the stimuli were separated by an interstimulus interval (ISI) that varied randomly around $1,050 \mathrm{msec}$, in the range between 950 and $1,150 \mathrm{msec}$. The irregular temporal spacing of stimuli ensured that the observers responded to the duration of stimuli per se, rather than to the rhythm or beat that would be created if the ISI were held constant. The experiment terminated only upon the recording of six responses at each of the 9 temporal durations for the oddball. The PSE was obtained by taking the $50 \%$ point of a Weibull fitted curve.

\section{Results}

The point at which the observer responded "longer" on half the trials was taken to be the PSE. PSEs listed were obtained from Weibull fitted curves. The average PSE was $675 \mathrm{msec}$ (Observer 1, PSE = $643 \mathrm{msec}$; Observer 2, PSE $=664 \mathrm{msec}$; Observer 3, PSE $=727 \mathrm{msec}$; Observer 4, PSE = $666 \mathrm{msec} ; S E=18.1 \mathrm{msec}$ ). Thus, an oddball (an expanding solid disk) lasting $675 \mathrm{msec}$ was judged to feel, on average, as long in duration as a standard lasting $1,050 \mathrm{msec}$. This is an example of TSE.

\section{EXPERIMENT 1B Temporal Dynamics of TSE for an Expanding Oddball}

In Experiment 1B, we tested the hypothesis that observers overestimate durations only after a temporal delay that corresponds to the number of milliseconds necessary for attention to be allocated to a new stimulus after onset of that stimulus. Again, we placed an expanding oddball of variable clock duration in a temporal sequence 
of standard events of constant clock duration. The observers' task was to say whether the oddballs lasted longer or less long than the standard events with which they were compared. The method of constant stimuli allowed us to determine the PSE for many different standard durations.

\section{Method}

Observers. For this experiment, we used 5 students who were not associated with our lab and 1 author (J.R.). The 5 student observers were male and female undergraduate and graduate students at Glendon College, York University, with normal or corrected-tonormal vision. Although they were aware that their task was one of duration judgment, they were naive regarding both the experimental hypotheses and the stimulus parameters.

Procedure. For each of the standard durations tested $(75,135$, $225,375,525,1,050$, and $2,100 \mathrm{msec}$ ), the oddball was tested at 9 objective durations around a central duration chosen to span a range that would permit the plotting of a psychometric function. The central duration was obtained by testing 13 objective durations over a wide range on two of the experimenters and using the average PSE obtained as the central duration for all other observers. Each standard duration in milliseconds is followed in parentheses by the test durations used: $75(30,45,60,75,90,105,120,135,150) ; 135(75$, $90,105,120,135,150,165,180,195) ; 225(75,105,135,165,195$, $225,255,285,315) ; 375(90,135,180,225,270,315,360,405$, $450) ; 525$ (240, 285, 330, 375, 420, 465, 510, 555, 600); 1,050 (450, $525,600,675,750,825,900,975,1,050) ; 2,100(1,125,1,275$, $1,425,1,575,1,725,1,875,2,025,2,175,2,325)$. Otherwise, all the methodological details were the same as those described for Experiment $1 \mathrm{~A}$. The ISI was randomized in the range of 950-1,150 msec for all the standard durations tested.

\section{Results}

Individual PSEs were calculated with the same method as that used above. The relationship of perceived to real durations was obtained by dividing the veridical duration of the standard by the PSE duration for the oddball, as shown in the following formula: temporal expansion factor $=$ standard time/PSE of oddball. An obvious consequence of this formula is that a low PSE implies a large temporal expansion factor. The individual data are shown in Figure 1. Note that each data point represents 54 oddball judgments within a stream of about 10 times that many standard disks.

The averaged data (arithmetic mean) for the expanding oddball among nonexpanding standards is shown in Figure 2. Note that there is no overestimation of duration for the $75-\mathrm{msec}$ case. Indeed, there is underestimation for the oddball at this low standard duration. However, already by $135 \mathrm{msec}$, there is considerable overestimation of the oddball's duration.

\section{Discussion}

According to the models described in the introduction, subjective durations are a function of the amount of temporal information processed over a perceived stimulus. If an enhancement of information processing occurs, subjective durations will seem longer than they might otherwise. Our results support this model. Interestingly, time does not appear to subjectively expand in this way until at least $\sim 120 \mathrm{msec}$ after stimulus onset. This result is consistent with the view that duration overestimation is a function of the allocation of attention, because attention presumably takes some time to allocate to the oddball target after it is detected.

But why would there be a reverse effect, or subjective temporal contraction, for the 75-msec case (compare Nakajima, ten Hoopen, Hilkhuysen, \& Sasaki, 1992; Nakajima, ten Hoopen, \& van der Wilk, 1991). If attention boosts the amount of information processed, the allocation of attention will boost perceived durations. However, attention takes some time to allocate. One possibility is that some information about a stimulus is lost before attention can be fully allocated to a stimulus. Information loss would lead to a relative shortening of perceived duration. Another possibility is that when the oddball target is detected at this brief duration, attention may be al-

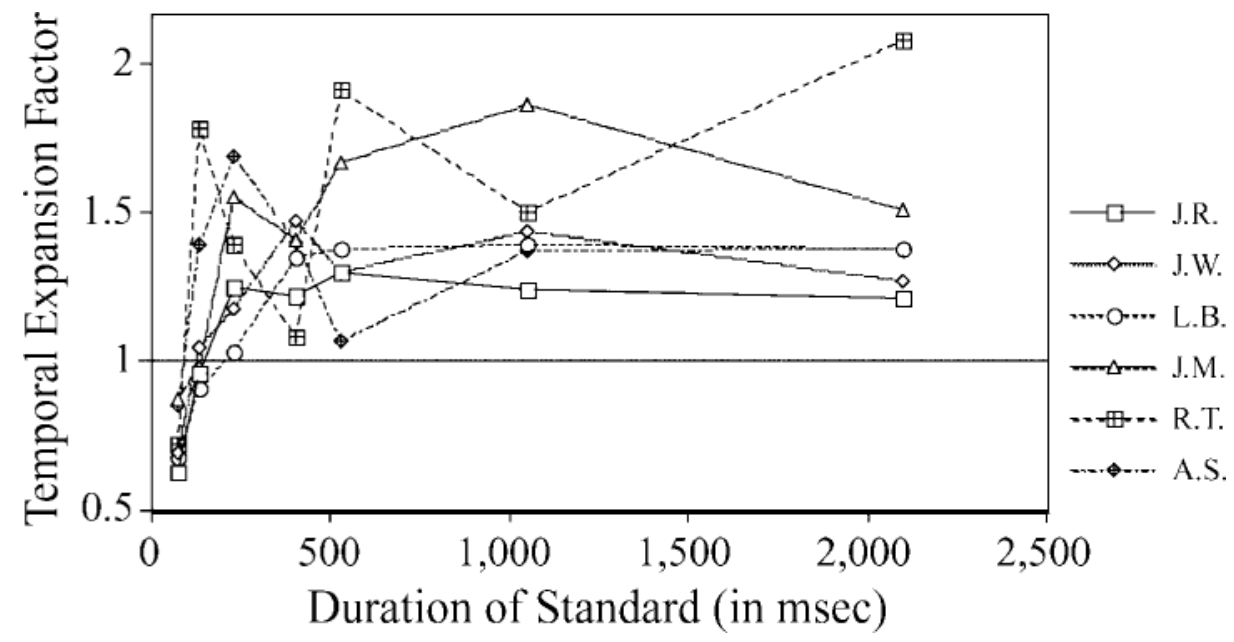

Figure 1. Individual data for 6 observers for an expanding oddball among nonexpanding standards. 


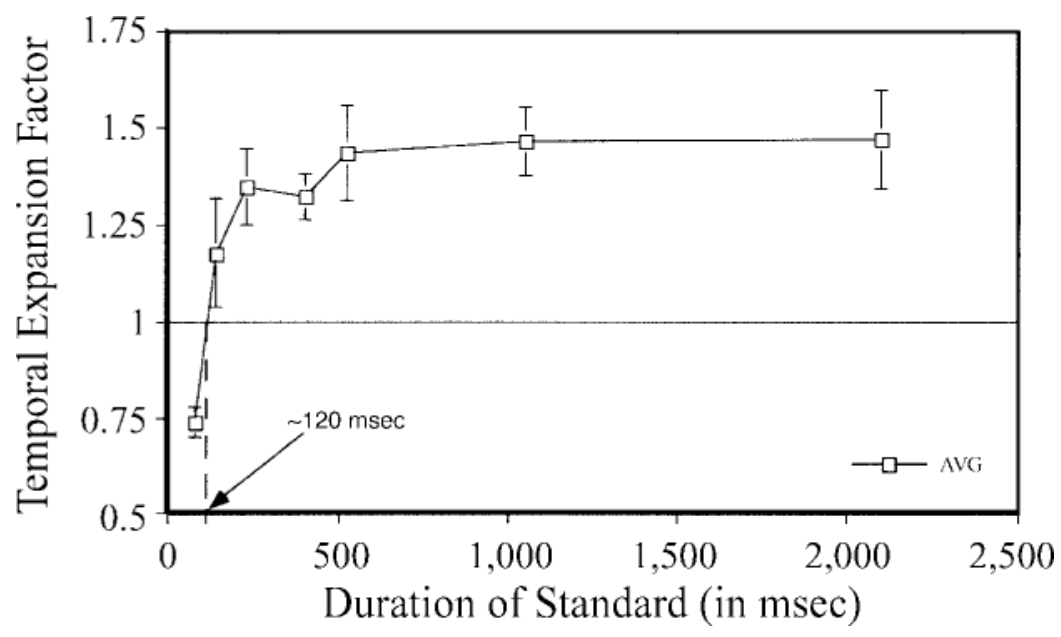

Figure 2. Average data for an expanding oddball among nonexpanding standards, using the method of constant stimuli, with standard errors of the means indicated by error bars.

located only after the target stimulus has disappeared. After the blank ISI, a standard stimulus appears on the screen. Because attention is now allocated to this stimulus, it is this standard disk that undergoes TSE. In relative terms, this standard will seem to last longer than the target that preceded it and observers may, therefore, respond "shorter" for the target more often than not. Another possible contributing factor may be that the blank ISI after the target's disappearance gets expanded. This may make the oddball, in retrospect, seem shorter. The temporal dynamics of attentional allocation may, therefore, contribute to subjective temporal contraction in more than one way.

An interesting observation about the curve shown in Figure 2 is that it has a dip centered at $375 \mathrm{msec}$ and a local peak at $225 \mathrm{msec}$. This peak and dip pattern is more consistent in the individual data shown in Figure 1. Of the 6 observers, only Observer L.B. did not demonstrate a peak followed by a dip followed by a rise in the temporal expansion factor. Indeed, because the dip occurs at different times for different observers, the size of the peak and dip is somewhat camouflaged in the averaged data shown in Figure 2. Assuming that attention is fully allocated to a stimulus only $\sim 120 \mathrm{msec}$ or more after the onset of that stimulus, this local peak would occur at $\sim 100 \mathrm{msec}$ after attentional allocation. Thus, this local peak happens in the neighborhood of $225 \mathrm{msec}$ after cue onset. If this peak-dip-rise pattern reflects real underlying processes, it is consistent with the existence of transient and sustained components of attention (Nakayama \& Mackeben, 1989). The transient component has a sudden onset, followed by a rapid decline, and the sustained component rises more slowly but does not fade as rapidly. According to Nakayama and Mackeben, the transient component peaks in the neighborhood of $100 \mathrm{msec}$ after cue onset and begins to decline approximately $200 \mathrm{msec}$ after cue onset. The transient peak in their data therefore tends to occur more rapidly than the peak in our data. The reason for this is unclear, but may be due to the differing nature of the two experimental paradigms.

In summary, the data shown in Figure 2 are consistent with a model of attention according to which (1) the amount of temporal expansion increases with the amount of temporal information processed and (2) attention enhances such information processing. Our data is consistent with the notion that attention takes on the order of $120 \mathrm{msec}$ to engage, once an oddball stimulus has been detected. The individual data, in particular, suggest that once engaged, a transient component of attention peaks within approximately $100 \mathrm{msec}$. As the transient component weakens, a sustained component of attention comes to dominate. It may be that the transient component induces a burst of temporal information processing that is greater than the rate of information processing that occurs during the sustained component phase. Therefore, the temporal expansion factor hits a peak with the peak of the transient component but stays above unity, because of enhanced information processing due to the sustained component of attention.

In this experiment, the occurrence of the oddball was confounded with the occurrence of expanding motion. Another potentially confounding factor was the rate or velocity of expansion, which depended on the duration of the oddball, because the ball had to grow from its initial to its final size within the time afforded by the allotted duration. Brown (1995) has shown that a moving stimulus tends to undergo more TSE than does a stationary stimulus of identical objective duration and that higher speeds tend to lengthen perceived time more than do lower speeds. Similarly, Fraisse (1963) argued that judged duration is a function of the number of perceived changes. Since an expanding stimulus has more perceived changes per unit objective duration than does a stationary stimulus, the 
TSE observed might be a consequence of change perception per se, rather than attentional orientation to an oddball. To address these potential confounds, the oddball in Experiment 2 was a stationary ball placed among a sequence of expanding standards.

\section{EXPERIMENT 2 Stationary Oddball}

It might be that the pattern of results shown in Figure 2 is not a consequence of the target's being an oddball so much as it is a consequence of the target's being a more salient stimulus. Thus, in this experiment, the role of target and standard in Experiment 1B were reversed.

\section{Method}

Observers. The observers $(n=6)$ were the same as those used in Experiment 1B. Three observers participated first in this experiment, and 3 participated first in Experiment 1B.

Procedure. Here, the oddball was a stationary disk among expanding standards. In every other respect, this experiment was identical to Experiment 1B. In particular, the standards included the same range of expansion velocities as that used in Experiment 1B.

\section{Results and Discussion}

The results are shown in Figure 3. Although the magnitude of TSE was less here than in Experiment 1B $(\sim 1.2$ here vs. $\sim 1.6$ for Experiment 1A and vs. $\sim 1.45$ for Experiment $1 \mathrm{~B}$ at 1,050 msec; compare Figure 4B), the overall pattern of results was very similar. Again, TSE occurred beyond $\sim 120 \mathrm{msec}$, and there was a peak-dip-rise pattern, although the peak occurred later in this case than in Experiment 1B. This trend is also discernible in the individual data. It could be that attentional orienting to a moving stimulus is faster than it is to a nonmoving stimulus. An extensive recent literature has shown that exogenous attention is allocated automatically and rapidly to a sudden onset or motion (Irwin, Colcombe, Kramer, \& Hahn, 2000; Jonides \& Yantis, 1988; Remington et al., 1992; Tse, Sheinberg, \& Logothetis, 2003; Yantis \& Egeth, 1999; Yantis \& Jonides, 1990). Because the oddball in this experiment involved only onset and no motion, it could be that transient or exogenous attention was allocated more slowly than in the case in which the oddball is moving, as in Experiment 1. Moreover, if attention is already at an elevated level because the standards are moving, the boost in attention afforded by the stationary oddball's novelty may take longer to rise to its peak level. Although we cannot say with certainty what delays the peak in TSE in this experiment, we can say with certainty that it is not solely the motion of the oddball that induces TSE. It is the fact that the target stimulus is an oddball to which the observer must respond that underlies the effect in this experiment.

In Experiment 1B, it is likely that the motion contributed to TSE, because the oddball was salient not only due to its relative novelty, but also due to its motion. In this experiment, however, it is likely that the inherent salience of the moving standards diminished the strength of TSE. This weakening of TSE might have had at least two nonexclusive causes. First, more attention may have been allocated to the standards, raising the baseline level of processing from which orienting to the oddball occurred. Second, the oddball may have drawn less attention to itself because of its relatively lower salience. In the next experiment, we determined whether TSE occurs for various other oddball stimuli.

\section{EXPERIMENT 3 Various Visual Oddballs}

In Experiment 3, we explored different types of oddballs presented within a series of standards. In this experiment,

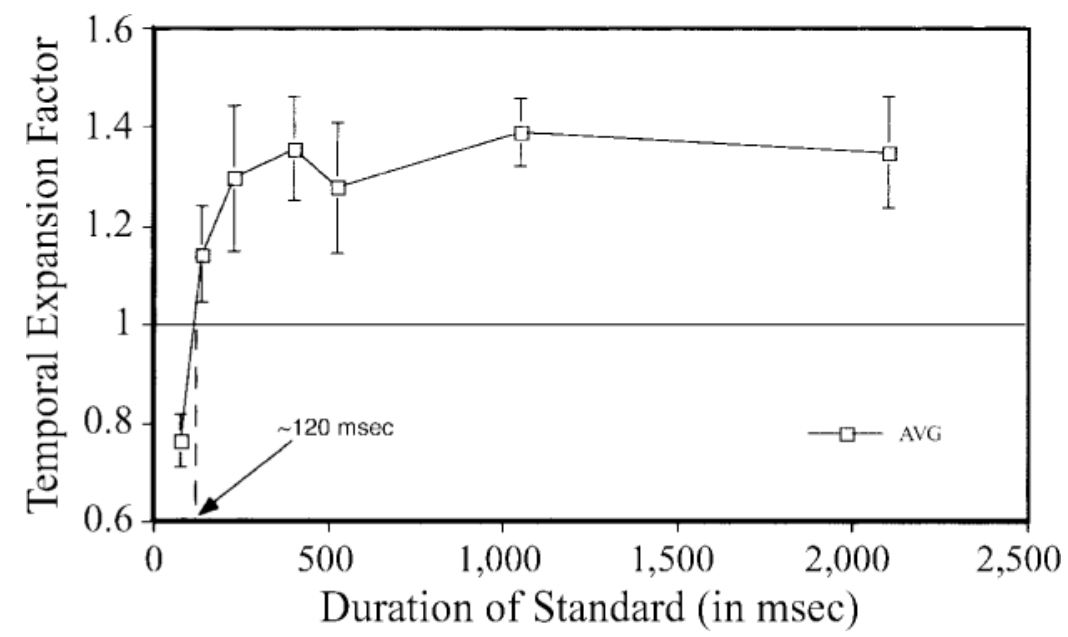

Figure 3. Average data for a nonexpanding oddball among expanding standards, using the method of constant stimuli, with standard errors of the means indicated by error bars. 
A

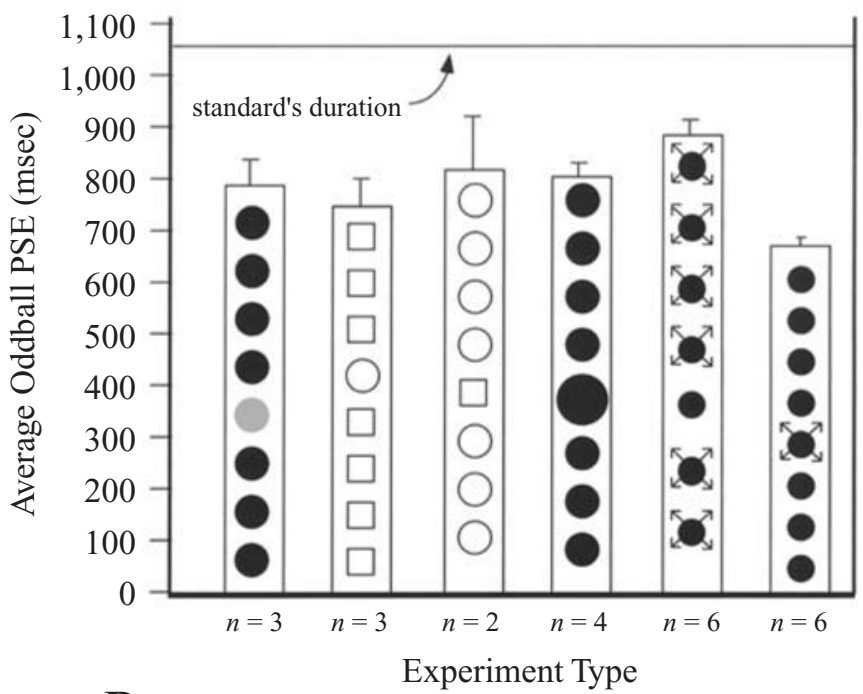

B

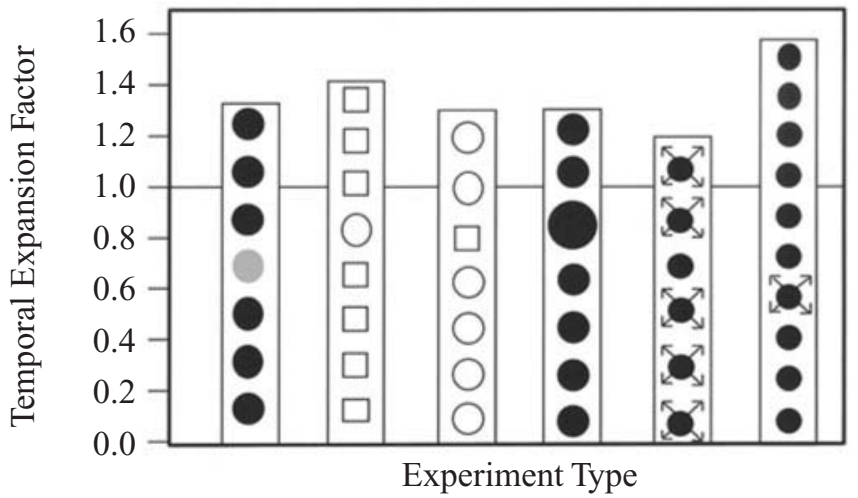

Figure 4. (A) Points of subjective equality (PSEs) for six types of oddball/standard combination. For example, the left-hand bar indicates a red oddball among black standards. The symbols for oddballs and standards are self-explanatory. The arrows indicate an expanding disk. Error bars indicate standard errors of the means. (B) Temporal expansion factors for various oddballs.

standards were always presented for 1,050 msec, ISI varied randomly around $1,050 \mathrm{msec}$, as in the previous experiments, and oddballs varied in objective duration as described in Experiment 1A. We tested a red stationary disk (radius, 63.6 arcmin) as an oddball among black stationary disks of the same size, a circle (radius, 63.6 arcmin) among squares (side length, 106.0 arcmin), a square among circles, and a large disk (radius, 211.7 arcmin) among the small disks (63.6 arcmin). The results for these oddballs will be compared with those for the expanding and stationary oddballs in the previous experiments.

\section{Method}

Naive observers were undergraduate and graduate students at Harvard University. The procedure was the method of constant stimuli, as described in Experiment 1B.

\section{Results and Discussion}

The results were again in psychometric form. PSEs were obtained from the $50 \%$ point of curves Weibull fitted to the raw data, which tended to be somewhat noisier than those obtained in Experiment 1A. The average PSEs and standard errors (in parentheses) were as follows: (1) red among black circles, $797.5 \mathrm{msec}(71.5 \mathrm{msec}), n=$ 3 ; (2) circle among squares, $760 \mathrm{msec}(78 \mathrm{msec}), n=3$; (3) square among circles, $823.5 \mathrm{msec}(130.5 \mathrm{msec}), n=$ 2; (4) large circle among small circles, $808.4 \mathrm{msec}$ (23.6 msec), $n=4,(5)$ black stationary circle among expanding circles, $858.8 \mathrm{msec}$ ( $36.43 \mathrm{msec}), n=6$, from Experiment 2 ; (6) expanding disk among stationary standards, $675 \mathrm{msec}$ (18.2 msec), $n=10$, combining data from Experiments 1A and 1B (Figure 2). These results are shown schematically in the bar graph in Figure 4A. 
The pattern within the bars of this bar graph is meant to indicate the type of standard and oddball stimuli used. For the sake of comparison, the final two bars illustrate the results from Experiments 1A, 1B, and 2. The rightmost bar indicates an expanding oddball among stationary standards. The second bar from the right indicates the stationary oddball among the expanding standards of Experiment 2 . The new data are shown in the four bars starting at the left. The leftmost bar was a red stationary oddball among black stationary standards. The next bar to the right shows data for a disk oddball among square standards, and the next bar shows the inverse case. The fourth bar shows data for a large oddball (radius, 100 pixels) among smaller standards (radius, 30 pixels). The number of observers used in each case is indicated at the base of each bar.

The strongest effect occurs in the rightmost bar, corresponding to Experiment 1B, where interobserver variability was also the lowest. In this case, as was discussed above, there may be factors contributing to the strength of the effect. For example, the expanding disk may be naturally more salient than the stationary standards among which it occurs, because it is moving. The weakest effect occurs in the fifth bar from the left, corresponding to Experiment 2 . Here, the strength of TSE may be diminished because the standards are now more salient than the target, by virtue of their motion (Brown, 1995). The other four cases are intermediate but generally support the notion that whenever an observer must detect and respond to an oddball stimulus, there will be a subjective temporal expansion. The same data have been replotted in Figure $4 \mathrm{~B}$ in terms of the temporal expansion factors found in the various conditions.

\section{EXPERIMENT 4 An Auditory Oddball}

If the curve shown in Figure 2 is due to the effects of a central process, such as attention, rather than a specif- ically visual process, repeating Experiment 1B using sound analogues of the standards and the expanding oddball should result in a similar curve. Alternatively, if the process is specifically visual, we might expect a different pattern of results.

\section{Method}

This experiment used two types of tones presented with stereo headphones; the standard tone was a pure sinusoidal tone set at middle $\mathrm{C}$, and the oddball tone was a smoothly rising tone that started at 20 half-notes below middle $\mathrm{C}$ and rose to 30 half-notes above middle C. Special care was taken to control the timing of this oddball. In all other respects, the experiment was identical to Experiment $1 \mathrm{~B}$ and used the method of constant stimuli with random ISIs.

Observers. Four observers, 1 experimenter and 3 naive observers, were used. Two of the 3 naive observers were trained psychophysicists and were not among the authors.

\section{Results and Discussion}

Individual data for the 4 observers are shown in Figure 5. Of particular interest is the relationship of the averaged data for this auditory experiment and the curve for its visual analogue (Figure 2). To make the relationship of these two curves apparent, they have been overlaid in Figure 6. Even though there is more TSE for the visual case at longer durations, the basic pattern of results is similar for the visual and the auditory conditions. Indeed, the auditory data are virtually identical to the visual data for a stationary oddball among expanding standards (Figure 3). We therefore conclude that TSE is due to a central process, such as attention.

Our data partly corroborate those of Nakajima and colleagues (Nakajima et al., 1992; Nakajima et al., 1991; see Allan \& Gibbon, 1994), who reported that empty durations seem relatively shorter than a preceding $50-\mathrm{msec}$ standard when the duration of the test stimulus is less than between 120 and $160 \mathrm{msec}$. However, they did not find TSE beyond $160 \mathrm{msec}$, as we do, but reported that "time-shrinking" merely goes away. This could be be-

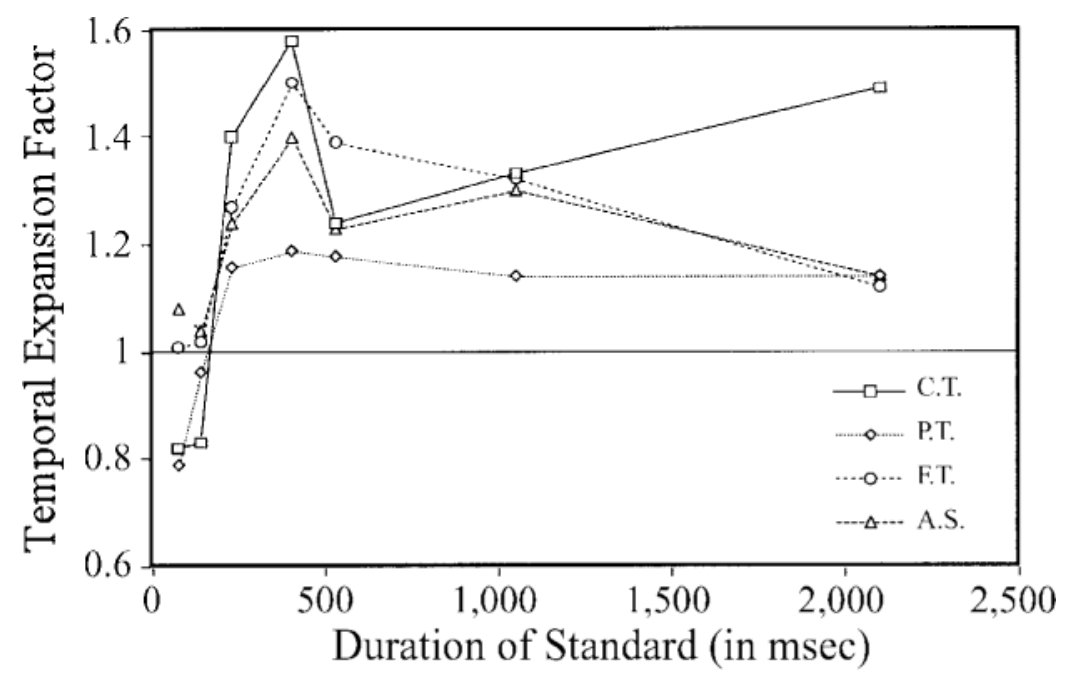

Figure 5. Individual data for a sound oddball among sound standards. 


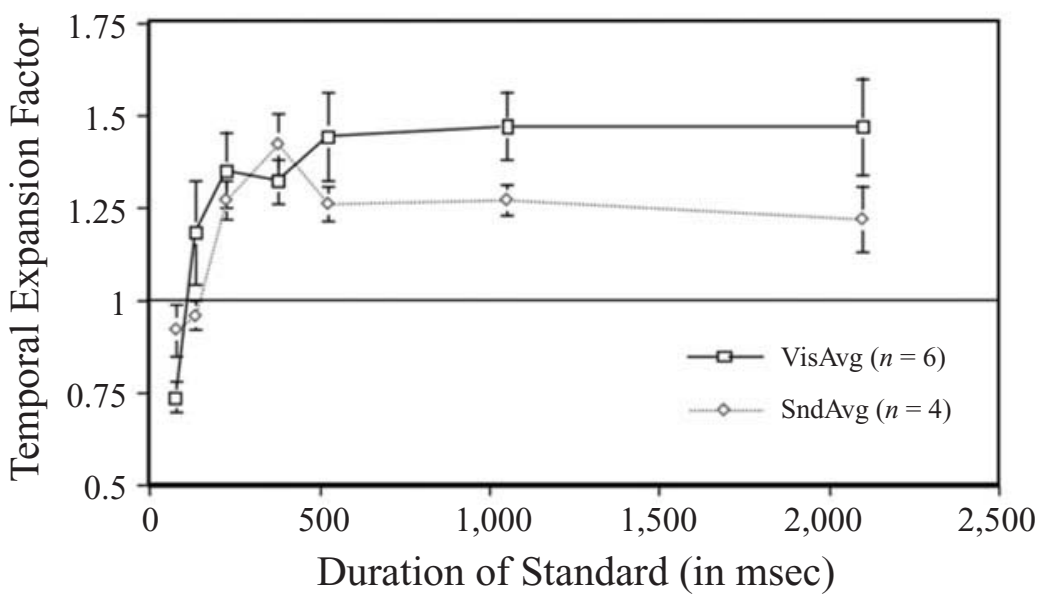

Figure 6. A comparison of the temporal dynamics for time's subjective expansion for both the visual and the auditory domains. The auditory data are the averages of the data shown in Figure 5. The visual data are reproduced from Figure 2.

cause they studied empty intervals, whereas we studied intervals filled with events. TSE may not be as strong an effect for empty intervals, because there is nothing to attend to in empty intervals except, perhaps, to the experience of time itself.

Note that both the visual and the auditory curves in Figure 6 suggest that TSE begins to occur in the neighborhood of 120-150 msec. This is consistent with the hypothesis that a brief span of time is required before attention can be allocated to a stimulus following stimulus onset. In addition, note that the auditory curve has a peak that is suggestive of a transient component. However, its peak occurs $150 \mathrm{msec}$ after the local peak at $225 \mathrm{msec}$ that is evident in the visual curve. This trend is not an artifact of having averaged data across observers. In Figure 1 , the peak occurs (for 5 of the 6 observers who do have a peak) between 135 and $375 \mathrm{msec}$, with 4 of the 6 observers demonstrating a peak at or before $225 \mathrm{msec}$. In contrast, all 4 observers in the auditory condition demonstrate a peak at $375 \mathrm{msec}$. The reason for this is unclear but may be due to differences in the temporal dynamics of the transient and the sustained components of attention in different sensory modalities. On the other hand, the peak and dip in the visual case shown in Figure 3, where the oddball was a stationary disk among expanding standards, occurs at the same durations (375 and $500 \mathrm{msec}$, respectively) as those found in the auditory case. Thus, slight differences in the locations of the peak and the dip may be less important than the fact that there is a peak and dip in both the auditory and the visual sense modalities. We take the existence of a peak and a dip, followed (at least in the visual cases shown in Figures 2 and 3 ) by a rise, to suggest that transient and sustained components of attention have differing temporal dynamics, as was described in Nakayama and Mackeben (1989).

\section{EXPERIMENT 5 The Method of Magnitude Estimation}

It might be that the curve shown in Figure 2 emerges as a consequence of some unforeseen confound in the method of constant stimuli itself. Because the oddballs were interspersed among several hundred standard disks in Experiment 1B, the observers tended to get very bored with staring at a screen of blinking disks, waiting for the oddball to appear, especially for longer test durations, when a given session could last as long as an hour. To corroborate the temporal dynamics shown in Figure 2, the less precise, but more rapid, method of magnitude estimation was used.

\section{Method}

Observers. The observers were 1 author and 3 naive graduate students from Harvard University. All had normal or corrected-tonormal vision.

Procedure. The observers fixated a stream of several standard disks of constant duration within a given trial. Each trial consisted of between five and seven standards, followed by the expanding oddball, which was in turn followed by between three and five standards. As in the previous experiments, the ISI varied randomly between 900 and $1,150 \mathrm{msec}$. The oddball was always the same objective duration as the standards. For each trial, the observer had to type in a number between 0 and 3.0 to indicate how many times longer the oddball felt, as compared with the standard. Once this was done, the observer initiated a new trial by pressing the space bar. A number less than 1.0 meant that the oddball felt shorter, and a number greater than 1.0 meant that the oddball felt longer. For example, 0.7 meant that the oddball felt only $70 \%$ as long as the standards, whereas 1.2 meant it felt $120 \%$ as long. After each trial, the observer would press a button to start a new trial, which would test a duration selected randomly from all the durations tested. Three trials were tested at each of the following durations: 70, 135, 225, $375,525,1,050,2,100$, and 4,200 msec. The 4,200-msec point was added in this experiment because the method of magnitude estima- 


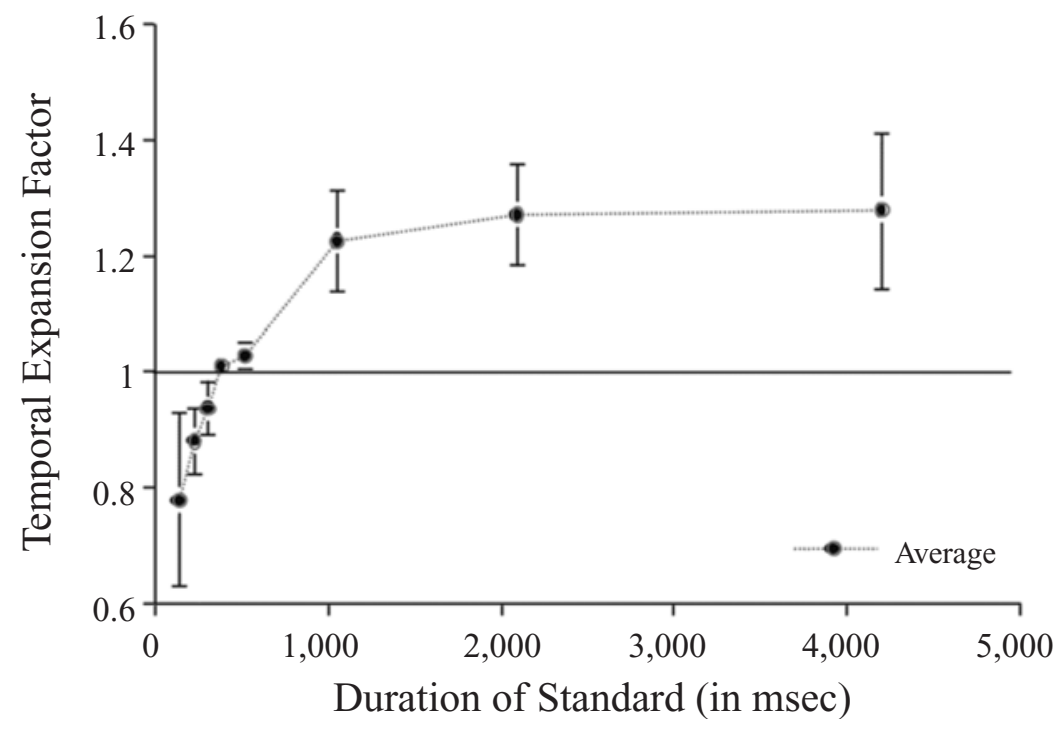

Figure 7. Average data for expanding oddball using magnitude estimation $(n=4)$. The temporal dynamic found using the method of magnitude estimation coincides with that found using the method of constant stimuli.

tion is fast. Gathering data at this duration with the method of constant stimuli, as in Experiment 1B, would have taken a prohibitively long time.

\section{Results and Discussion}

Data for the 4 observers tested are shown in Figure 7. The basic pattern of results found here with the method of magnitude estimation is consistent with that found in Experiment 1B with the method of constant stimuli, suggesting that the underlying phenomenon is real and that the results are robust. We can conclude that observer boredom induced by the method of constant stimuli in Experiment $1 \mathrm{~B}$ was not the primary cause of the pattern of results shown in Figure 2, since a similar pattern of results is evident in Figure 3. However, there are two discrepancies. One difference is that results with the method of magnitude estimation may indicate a later onset of TSE. The intersection with the line where the temporal expansion factor equals unity is at approximately $375 \mathrm{msec}$. Perhaps this discrepancy can be blamed on the inherent imprecision of this method, or perhaps attention was allocated more slowly in this experimental paradigm. A second discrepancy is the absence of a transient peak or peak-dip-rise pattern. Again, this may be due to the imprecision of this method. Or it may be that such a peak does not arise when this method is used as a probe of TSE. One difference between this method and the method of constant stimuli used in the earlier experiments is that observers had to perform several hand movements between trials to enter their response and trigger the next trial. This may have kept the observers from becoming as bored as they did in Experiments 1-3, where the observers had to stare continually at the computer screen for long periods of time, in anticipation of an oddball's occurrence. It may be that the degree of surprise associated with the occurrence of an oddball was greater in Experiments $1-3$. If so, the transient component of attention may have contributed more to the results shown in Figure 2 than to the results shown in Figure 7. In Experiment 6 , we further corroborated the reality of the temporal dynamics of TSE with a very different psychophysical method.

\section{EXPERIMENT 6}

\section{The Method of Stimulus Duration Reproduction}

In this experiment, we used the method of physical reproduction of the duration of a stimulus. Our goal was to determine whether the trend revealed by the curve shown in Figure 2 occurs in instances in which the observer responds by pressing a button for as long as the test stimulus appears to last. This method is similar to the method of magnitude estimation. However, instead of estimating how long the stimulus appeared to last as a proportion of the apparent duration of the standard, the observers reproduced just the apparent duration of the test stimulus. If the underlying effect is robust, the same pattern of results as that shown in Figure 7 should also emerge here.

\section{Method}

Observers. The observers consisted of 1 experimenter and 3 naive observers, 1 of whom had previously participated in Experiment 1A.

Procedure. Five black disks on a white background blinked in succession in the center of the computer screen. Each disk remained visible for the same duration within a trial, and the five disks of a trial were separated by ISIs that varied randomly around the duration of the disks. The observers were instructed to press a computer key for the precise duration of the final stimulus. The duration of the stimuli varied between trials randomly, although within each trial all 


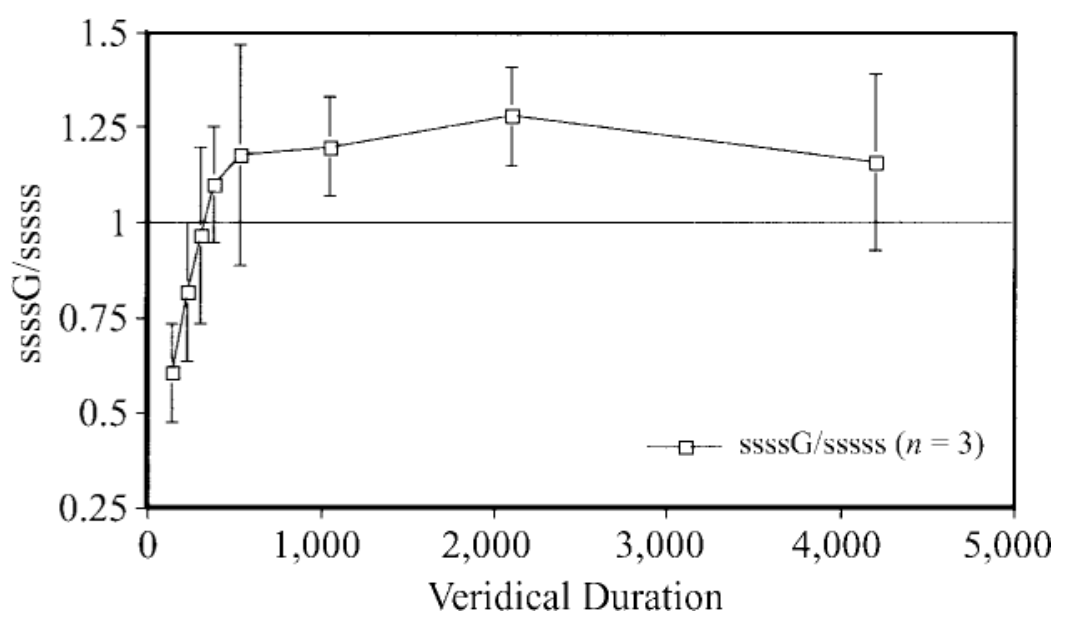

Figure 8. The reproduced durations for ssssG and sssss trials conform to Vierordt's law.

the stimuli were of the same duration. Eight durations were tested: $135,225,300,375,525,1,050,2,100$, and 4,200 $\mathrm{msec}$. There were two types of trials: (1) sssss trials, in which all five stimuli were small black disks with a radius of 63.6 arcmin and (2) $s s s s G$ trials, in which the final stimulus was a disk that grew from 63.6 arcmin to 211.7 arcmin within the duration of the stimulus.

\section{Results and Discussion}

As can be seen in Figure 8, the observers tended to press the button for longer than was veridical when the stimulus was brief, and they tended to press the button for too short a duration when the stimulus duration was long. This replicates Vierordt's (1868) law, according to which short intervals are overestimated and long intervals underestimated when the method of stimulus reproduction is used. These results may well be contaminated by motor/ effector systems, reaction time limitations, and other factors that have nothing to do with the perception of duration per se. Thus, the important data for our purposes are the ratio of reproduced durations for ssssG trials to reproduced durations for sssss trials. Contaminating factors are presumably identical for both types of trials and should, therefore, cancel out in the ratio. Moreover, it has been reported that the position of a stimulus in a train of stimuli can affect its perceived duration (Rose \& Summers, 1995). But because the target appeared in the same position in sssss and ssssG trials, any effect due simply to stimulus position should cancel out when the ratio is taken. This ratio should also cancel out any other artifacts due to the method itself and reveal the underlying relationship between the subjective duration of the expanding disk to the subjective duration of the nonexpanding disk. As such,

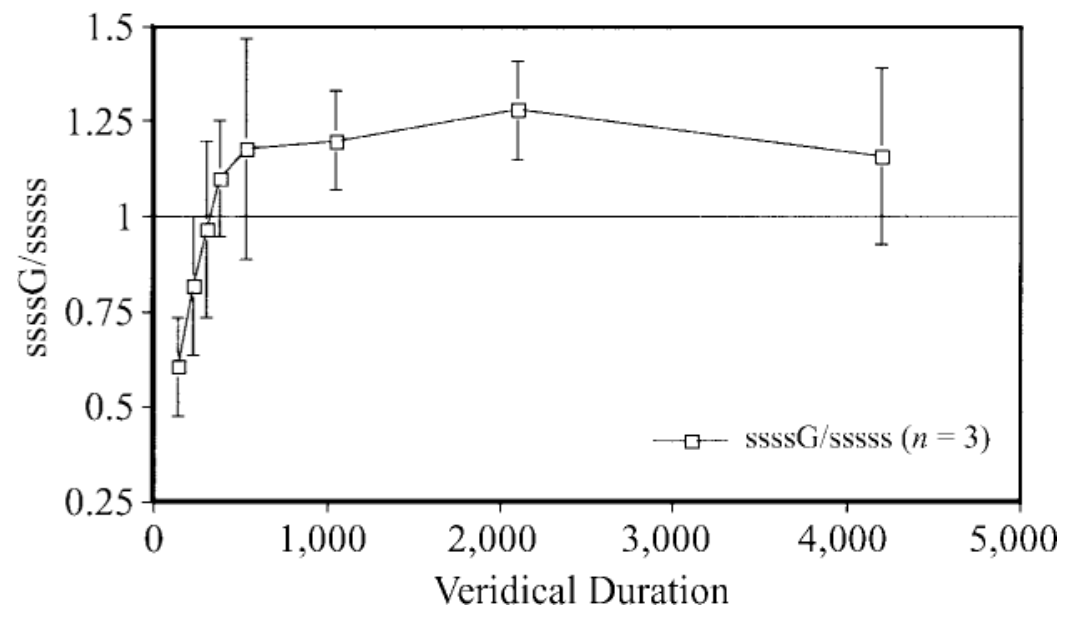

Figure 9. The ratio of reproduced durations for ssssG trials to reproduced durations for sssss trials, using the method of stimulus duration reproduction. Error bars indicate standard errors of the means. 
this ratio should, in principle, be equivalent to the temporal expansion factor described in Experiment 1B. These data are shown in Figure 9.

Note that the general temporal dynamics of the data are similar to those found in the data obtained with the method of constant stimuli (Experiments 1 and 2) and the method of magnitude estimation (Experiment 5). The underlying phenomenon therefore appears to be robust and measurable with a number of different psychophysical techniques. Again, however, the crossover duration to the TSE domain occurred later than in Experiments 1-4, and there was a lack of the peak TSE at $225 \mathrm{msec}$ found with the method of constant stimuli.

\section{EXPERIMENT 7 The Method of Single Stimuli}

This control experiment was done to address two possible confounds in Experiments 1-6. First, it is possible that the temporal expansion effects were not due to the oddball's being an oddball but, instead, to the fact that the oddball was the only stimulus to which the observer must respond. To address the potential confounding of oddball detection and response, we devised an experiment in which the observers had to physically respond to each stimulus. A second possible confound in Experiments $1-5$ was that the oddball was an oddball both in terms of its image properties and in terms of its higher order "meaning" for the observer. Thus, for this experiment, we created 200 stimuli, each of which was novel in terms of its image properties, but each of which fit into only two semantic categories. The observer had to categorize stimuli by using these categories. In the present experiment, one stimulus type was termed an oddball simply because it had a lower probability of occurrence than the other type.

\section{Method}

Stimuli. The stimuli consisted of 200 images of mannequin-like male (100 images) and female (100 images) adult bodies of approx- imately the same height $\left(15^{\circ}\right.$ tall at a viewing distance of $\left.57 \mathrm{~cm}\right)$. Each was given a unique bodily posture and limb placement chosen to look like a natural position. These images were generated using a software package called Poser 2.0 (Weinberg, 1991-1995) for the Macintosh. Examples of the stimuli are shown in Figure 10.

Procedure. The method of single stimuli first developed by McKee (e.g., McKee, Klein, \& Teller, 1985) was used. The observer's task was to judge whether each stimulus lasted longer or less long than the average of all previously presented stimuli. The observers pressed one computer button if the stimulus felt longer than average and another if the stimulus felt shorter than average for each stimulus in a two-alternative forced choice (2AFC) paradigm. To do this, the observers had to be able to form an internal representation of the average duration of all the previously presented stimuli.

Male and female mannequin stimuli were presented at differing probabilities of occurrence. Either females appeared randomly with a $10 \%$ probability within a stream of males that appeared with a probability of $90 \%$, or males appeared randomly with a $10 \%$ probability within a stream of females that appeared with a probability of $90 \%$. Each observer participated in both types of trials. Five observers ran in the male oddball trial first ( $90 \%$ females, $10 \%$ males), and $5 \mathrm{ran}$ in the female oddball trial first $(90 \%$ males, $10 \%$ females). In both types of stimulus streams, the less probable stimulus appeared 60 times, and the more probable stimulus appeared 540 times. Because the 60 low-probability test images were chosen at random (with removal) from a set of 100, each was novel. However, because there were only 100 of either stimulus type, the highprobability stimulus was repeated, on average, 5.4 times, since 540 images were selected at random from 100 images. Once 100 highprobability stimuli had been shown, stimuli were again selected from the same set of 100 at random with removal. The less probable stimulus was made significant for the observers because they were required to perform the concurrent task of counting the less probable stimuli. The observers were told whether to count the female or the male stimuli at the beginning of the respective trial sequence. We decided to include this minimally difficult concurrent task because, in trial experiments, the observers stopped paying attention to the stream of stimuli if not required to process the stimuli in some way. In trial experiments, we required the observers to count both the number of oddballs and the number of standards. This proved far too difficult, so we settled on having them count only the oddball stimuli. Because a concurrent task in which observers are required to attend to nontemporal information typically decreases the degree of TSE (e.g., Grondin \& Macar, 1992; Hicks \& Brundige, 1974; Hicks et al., 1976; Hülser, 1924; Katz, 1906; Macar et al., 1994; Predebon, 1996; Quasebarth, 1924; Thomas \&
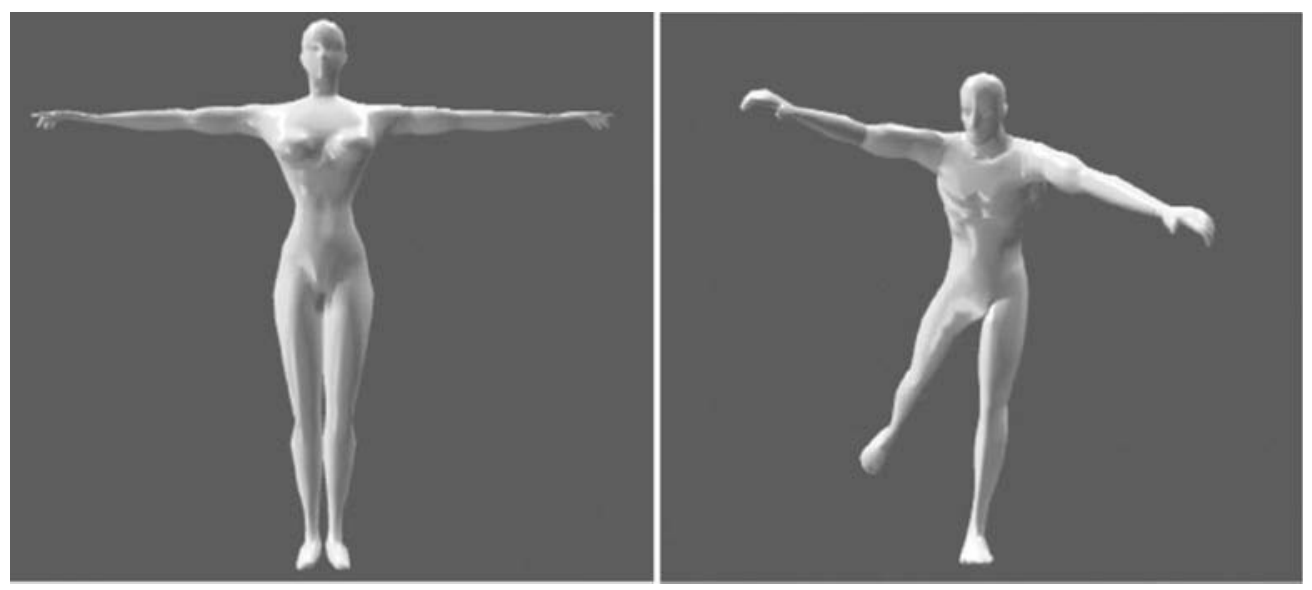

Figure 10. Examples of the mannequin stimuli used in Experiment 7. 
Cantor, 1978; Underwood \& Swain, 1973; Zakay, 1993; Zakay \& Tsal, 1989), we reasoned that this task worked against our hypothesis and, so, was a conservative measure.

The durations of both female and male stimuli varied randomly around a mean of $1,050 \mathrm{msec}$. As in the previous experiments, each stimulus was separated by an ISI that varied randomly around a mean of 1,050 msec. Nine durations $(690,780,870,960,1,050$, $1,140,1,230,1,320$, and $1,410 \mathrm{msec}$ ) were tested for each stimulus type. Ten of the low-probability stimuli were randomly shown six times for each of the nine test duration conditions. Similarly, 54 of the high-probability stimuli were randomly shown six times for each of the nine test duration conditions. This permitted us to obtain a psychometric function for both types of stimuli independently. A PSE was obtained for both male and female stimuli on the basis of Weibull curve fitting of the data.

\section{Results and Discussion}

All the observers counted the less probable stimulus correctly within an accuracy of $10 \%$, suggesting that they were able to distinguish the stimuli as male or female quite easily and had paid attention to the task. The average difference between the PSE for the stimulus that was presented with a $90 \%$ probability and the PSE for the stimulus that was presented with a $10 \%$ probability was $92.4 \mathrm{msec}$ overall. The average of the two $90 \%$ PSEs for each observer was significantly different from the average of the two $10 \%$ PSEs at the .05 level, as measured using a one-way analysis of variance [ANOVA; $F(1,18)=$ $9.44, p=.007]$. However, the average male stimulus PSE for each observer did not differ significantly from the average female stimulus PSE, as determined using a one-way ANOVA $[F(1,18)=1.48, p=.24]$. Thus, lowprobability stimuli undergo temporal expansion relatively more than do high-probability stimuli because they are a low-probability stimulus, not because they happen to be male or female.
The average PSEs for the 10 observers tested are shown in Figure 11A for both conditions. The less probable stimulus had a smaller PSE than did the higher probability stimulus for every trial of every observer. Because a smaller PSE implies a greater temporal expansion factor or a greater subjective expansion of time, we can infer that the less probable stimulus tended to last longer subjectively. The TSE for the less probable stimulus type, relative to the more probable stimulus type, is made apparent in Figure 11B. In this figure, the temporal expansion factor was calculated by dividing $1,050 \mathrm{msec}$ (the true average stimulus duration for both stimulus types) by the PSE for the stimulus type. The data for all the $90 \%$ probability stimuli (20 measurements from 10 observers in two conditions) were used to determine the temporal expansion factors shown in Figure 11B.

What is important in Figure 11B is the relative difference between the temporal expansion factors for the lowand the high-probability stimuli, not the absolute value. The PSEs in Figure 11A could have arisen from an observer bias to say that a stimulus appeared shorter in duration than the internally represented cumulative average. These data could also have been biased, if the running subjective average was longer than the true average. Since longer stimuli would tend to undergo TSE, this might bias the subjective average to be longer than the objective average. If there were no bias, we would expect the PSE of the high-probability stimulus to be $1,050 \mathrm{msec}$. In fact, the average PSE for the $90 \%$ probability stimuli was, on average, 1,147.7 msec. If the PSEs in Figure 11A were not, perhaps, subject to bias, we would have to conclude that both high- and low-probability stimuli were contracted and that the rare stimulus was less contracted than the common one. This would indeed be a peculiar
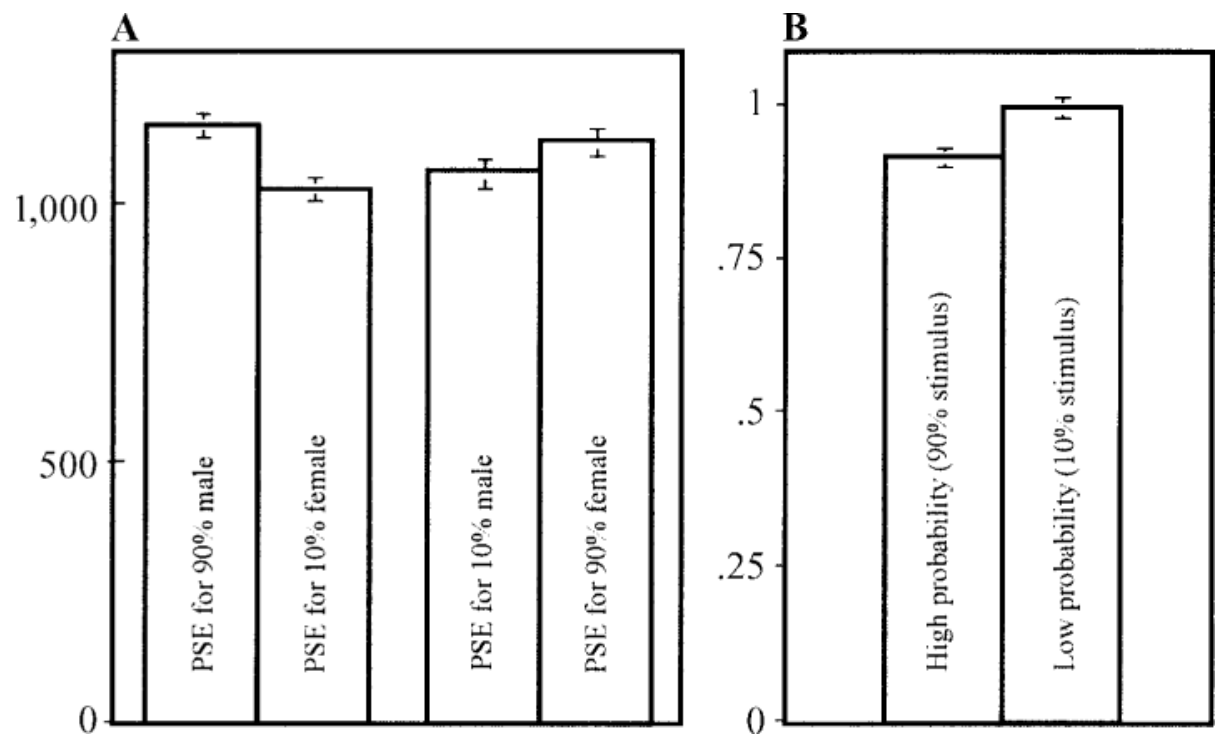

Figure 11. (A) Average points of subjective equality (PSEs) for male (90\%)/female (10\%) and for male $(10 \%) /$ female $(90 \%)$ cases. (B) The low-probability stimulus has a higher average temporal expansion factor. Error bars indicate standard errors of the means. 
finding, akin to saying that everyone is below average. Because the absolute values of the PSEs are not interpretable, we have to limit discussion to the relative differences between the PSEs for the two types of stimuli. To quantify the relative difference between the two stimulus types, an average temporal expansion factor can be calculated by dividing the average PSE for the $90 \%$ probability stimuli $(1,147.7 \mathrm{msec})$ by the average PSE for the $10 \%$ probability stimuli $(1,055.3 \mathrm{msec})$. This temporal expansion factor (1.09) is relatively low, although the effect is significant. In comparison, the temporal expansion factor for an expanding disk among 1,050-msec standard nonexpanding disks is greater than 1.5 (see Figure 4). The difference in the strengths of the temporal expansion factors in this experiment and in Experiment 1B may be due to the different task demands of the two experiments. In Experiment 1B, the observers did not have to pay much attention to the standards, since they had to respond only to the oddballs. Thus, when the oddball did appear, there was presumably a relatively larger orienting or attending response. In this experiment, however, the observers had to attend to each stimulus rather carefully to determine its gender and to determine its duration relative to the average duration of all the previously presented stimuli. Thus, the jump in the level of attending may have been less for oddballs within this paradigm. Also, as was noted previously, the stimuli in Experiment 1B are likely to have been inherently more salient because of their motion (Brown, 1995). Note that in Experiment 2, where the standards were moving and the oddball was stationary, the temporal expansion factor was only about 1.2 , which is similar to the degree of expansion we find here. Lastly, the counting that the observers carried out for oddball stimuli probably worked against TSE, because a nontemporal concurrent processing task is known to decrease perceived duration, rather than increase it (e.g., Grondin \& Macar, 1992; Hicks \& Brundige, 1974; Hicks et al., 1976; Hülser, 1924; Katz, 1906; Macar et al., 1994; Predebon, 1996; Quasebarth, 1924; Thomas \& Cantor, 1978; Underwood \& Swain, 1973; Zakay, 1993; Zakay \& Tsal, 1989).

This control experiment placed certain constraints on the nature of TSE. First, because each individual stimulus occurred with low probability, it was approximately novel in image coordinates. Thus, TSE occurred not because the oddball had a low-probability image configuration, but because the oddball was a low-probability type of stimulus. This suggests that the process that generates TSE is one that has available to it processed information about a stimulus, such as its semantic category. Second, TSE was not due to a physical response bias, since in this experiment the observers had to physically respond to each stimulus, not just to the less probable stimulus.

\section{GENERAL DISCUSSION}

When observers' sole task is to judge duration, the ratio of estimated to real duration generally increases as a function of the amount of information in the judged interval (regarding the number of stimuli, see, e.g., Fraisse, 1963; Ornstein, 1969; Thomas \& Brown, 1974; on the complexity of those stimuli, see, e.g., Avant et al., 1975; Schiffman \& Bobko, 1974; Thomas \& Weaver, 1975). Conversely, the ratio generally decreases as a function of the amount of information processed in a distracting secondary task (e.g., Grondin \& Macar, 1992; Zakay \& Tsal, 1989). We agree with the traditional view (e.g., Creelman, 1962; Thomas \& Weaver, 1975; Treisman, 1963) of time perception, according to which perceived duration is a function of the amount of information processed per unit of objective time. We also accept the standard view that attention can influence the perception of duration (e.g., Brown, 1985; Cantor \& Thomas, 1977; Creelman, 1962; Fraisse, 1963, 1984; Hicks et al., 1977; Hicks et al., 1976; James, 1890/1950; Katz, 1906; Mattes \& Ulrich, 1998; Thomas \& Brown, 1974; Thomas \& Cantor, 1978; Thomas \& Weaver, 1975; Treisman, 1963). According to the general approach in these works, there is a counter that keeps track of the number of units of temporal information processed for a given perceived event (Thomas \& Weaver, 1975; Treisman, 1963). These models argue that some proportion of the units of temporal information is typically missed, especially when other tasks distract attention from monitoring the temporal markers. An increase of attention to the duration judgment itself results in fewer temporal cues being missed, thereby lengthening the apparent duration. These two factors account for the general pattern of reported time distortions.

Our findings are consistent with a modification to this model. Specifically, the engagement of attention by an unexpected event may not simply reduce missed information but may actually increase the rate of information processing brought to bear on a stimulus. More units are detected during the event, and it therefore seems to last longer, but this occurs because there are more units, not because fewer are missed. In the previous hypothesis, it is assumed that attention affects sensitivity, leading to fewer missed cues in a stream of constant rate. The modification we propose here is that sensitivity remains unchanged by attention but the rate of information processing increases. These interpretations are not mutually exclusive. Both could contribute to distortions in perceived duration, and both are compatible with the notion of a counter that measures the amount of information processed in order to calculate the duration of perceived events. For either reason, an attended stimulus may appear to last longer than a less attended stimulus that lasts the same objective duration. Our data do not distinguish between these possible mechanisms of enhanced information processing. ${ }^{2}$

We used an oddball paradigm to explore distortions in subjective time, under the assumption that observers orient or attend to a low-probability stimulus more than they do to a high-probability stimulus. The goal of this article was to probe the objective temporal dynamics of TSE in order to determine whether the effect is truly at- 
tentional. Although we used four different psychophysical methods, we place greatest stock in the results obtained with the method of constant stimuli (Experiments 1-4), because the other three methods are inherently less precise. The method of constant stimuli is a $2 \mathrm{AFC}$ method with a reference standard available both before and after each temporal judgment has to be made. In contrast, the methods of magnitude estimation (Experiment 5) and duration reproduction (Experiment 6) are not 2AFC methods. Observers have to either verbally or motorically gauge duration on an open-ended scale that is vulnerable to report bias. As such, the absolute temporal expansion factors are not particularly meaningful. One can say only that the temporal expansion factor at duration $x$ is greater or less than that at duration $y$. Similarly, the method of single stimuli (Experiment 7) is also a "rough" measure of TSE, because it requires observers to create and continually update a long-term memory of duration. Besides introducing errors that may have more to do with longterm memory than with time perception, this method is vulnerable to observer biases to consistently report stimuli as longer or shorter than the running average. As such, the absolute PSE or temporal expansion factor determined with this method is not meaningful, although the relative temporal expansion factor (1.09 in Experiment 7) is meaningful, since any biases should cancel out in the ratio. The only method for which there can be an absolute, and not just a relative, temporal expansion factor is the method of constant stimuli. Although data collection using this method is much more time consuming than the other methods, it offers the clearest picture of the temporal dynamics of TSE. For example, there is always a peak in the TSE (Experiments 1-4) found when the method of constant stimuli is used that is not apparent in the temporal dynamics of TSE determined when either the method of magnitude estimation (Experiment 5) or the method of duration reproduction (Experiment 6) is used. We believe that although these methods measure the same basic underlying effect, they are more prone to noise and bias and, therefore, may be too insensitive to detect the transient peak in TSE seen with the method of constant stimuli, at least for the number of observers used here. In future work, we will limit data collection to the method of constant stimuli.

It may be impossible to establish beyond all doubt that TSE is caused by attentional allocation, and not by some other process associated with the onset of an oddball. Nonetheless, four properties of our data suggest to us that TSE is indeed a result of attentional allocation to the oddball. First, TSE does not begin until at least $\sim 120 \mathrm{msec}$ after stimulus onset. This may be due to the time it takes attention to be allocated to a stimulus after its onset. Second, in all of our experiments in which the method of constant stimuli was used (Figures 2, 3, and 6), the temporal dynamics of TSE were consistent with the contributions of two components, suggesting both transient and sustained components of attention. Third, approximately the same temporal dynamics were evident for both vi- sual and auditory modalities (Figure 5 ), suggesting that the mechanism that underlies TSE is central, rather than peripheral. Fourth, evidence that TSE is central in origin was found in Experiment 7, where it was shown that the effect can be found with high-level category novelty, rather than with just image novelty, because in that experiment, all the stimuli had a low probability of appearance. Experiment 7 also established that the effect is due to internal processing and is not just due to the act of physically responding, since the observers had to respond to each stimulus, rather than to just the oddball. Although none of our experiments can prove that TSE is attentional in origin, we feel that the evidence strongly implicates an attentional account. If TSE is not caused by attentional allocation, it is caused by some other process that occurs in response to the occurrence of an oddball event.

TSE may be an instance of a far more general phenomenon known as time order error (TOE), first described by Fechner $(1860,1882)$. TOE refers to the influence of the order of presentation of two stimuli on the perceived relative magnitude of those stimuli along some stimulus dimension, such as weight, loudness, length, or duration. Fechner noticed, for example, that when two identical weights are lifted in succession, the second one seems heavier. Other researchers have found similar asymmetries for identical stimulus pairs judged in sequential comparison along virtually every stimulus dimension ever tested (for a review of TOE, see Hellström, 1985). The second stimulus generally seems enhanced along the judged dimension when the sequential stimuli compared have a high magnitude along that dimension and seems diminished when the magnitude of the pair is low (Fechner, 1860; Pratt, 1933). Because high magnitudes are shifted upward and low ones downward across so many stimulus dimensions, TOE probably results from some process underlying how observers make judgments in general. Authors who have studied TOE in the comparison of successively presented temporal intervals (e.g., Allan, 1977, 1979, 1984; Jamieson \& Petrusic, 1975; Petrusic, 1984; Schab \& Crowder, 1988; Woodrow, 1930, 1951) have generally found that the second duration seems shorter than the first when both stimuli are short in duration and longer than the first when both stimuli are long in duration. Our results follow this basic pattern, with the point separating the temporal contraction and expansion zones centered at about $150 \mathrm{msec}$.

We are not convinced that TSE is an instance of TOE. TOE always involves a comparison of two sequentially presented stimuli, usually a standard and a test stimulus. Our data were collected within long trains of stimulus presentation for which standards were available both before and after oddball presentation. The observers were encouraged to use both these standards in making their judgments of duration, relative to the standard. TOE would predict TSE for a relatively long standard and oddball durations if observers used the standard presented before oddball presentation but would predict subjective tempo- 
ral contraction if observers used the standard presented after oddball presentation. There is also evidence that the first of a train of several stimuli of identical duration is perceived to last longer than the subsequent stimuli (Rose \& Summers, 1995). TOE would, however, predict that the second stimulus would appear longer for the durations tested. TOE is also dependent on the method used to measure it. Using the method of constant stimuli (Experiments 1 and 2), we found that longer durations are overestimated and shorter ones underestimated. But using the method of stimulus reproduction (Experiment 6), we found the opposite. Finally, there is no generally accepted cause of TOE. Fechner (1860) argued that the second weight seems heavier because of fatigue, an explanation that could not apply to our temporal paradigm. The TOE literature is complicated (Hellström, 1985) by the existence of at least a dozen competing theories.

One class of theories of TOE (Helson, 1947, 1964; Hollingworth, 1910; Leuba, 1892; Pratt, 1933) emphasizes the fact that observers judge the duration of the second stimulus not relative to the first one, but relative to a memory trace of the first one. If there is a tendency for this memory trace to regress toward the mean of all previous stimuli along the measured dimension, the second stimulus will tend to seem larger for high-magnitude and lower for low-magnitude stimuli. Our experiments required observers to remember the duration of a standard and, so, could also be subject to memory-induced illusions. Indeed, all experiments involving a comparison between a standard and a test duration must involve remembering one of those durations, since the standard and the test durations cannot be presented simultaneously, because then their onset and offset would be simultaneous, providing a cue to their common duration. In Experiment 1B, half the observers (see Figure 1) were tested on short-duration standards and oddballs first, and they showed the same basic temporal dynamics as those who were first tested using long-duration standards and oddballs. If the TSE can be explained using the regression to the mean of a memory trace, we would expect different temporal dynamics of TSE for the two types of observers. But we do not see this. Also, an account based on fatigue (Fechner, 1860), decay of a memory trace, or regression of a memory trace to a mean cannot account for other findings in the time literature. Again, the first stimulus in a train of stimuli tends to appear longer than subsequent ones (Rose \& Summers, 1995). Besides the fact that the findings go in the opposite direction from that expected on the basis of TOE, there can be no regression to the mean of all previous stimulus durations for the first stimulus. Note, however, that an attentional account can explain this result. The first stimulus draws attention to itself by being novel and, therefore, undergoes a greater boosting of information processing than do subsequent, less novel stimuli. This kind of TOE theory also cannot account for the peak we observe in the temporal dynamics of TSE when measured using the method of constant stimuli. Nor can memory-based the- ories of TOE account for the difference in the degree of TSE we see between Experiments 1 and 2. TSE is greater when the oddball is moving and the standards are stationary than in the reverse case. An attentional account can easily explain this difference, however, because the moving oddballs are more salient and, therefore, will be allocated more attention.

The TOE phenomenon may itself be attentional in origin. The theory that most comprehensively accounts for TOE data is the quantitative adaptation-weighting model of Hellström $(1977,1979,1985)$. The essence of this theory is "to associate different weights with the stimuli or, rather, with their corresponding sensation magnitudes. The weights will depend on the grouping and the relative attention paid to the stimuli" (Hellström, 1985, p. 42). Grouping is "based on similarity and spatial and/or temporal closeness." Following Festinger, Coren, and Rivers (1970), Hellström goes on to make an analogy between distortions due to TOE and brightness contrast: "the brightness difference between figure (the attended part of the field) and ground (the nonattended part) is symmetrically superimposed on the perceived average brightness, which is a weighted average of the brightness of all parts of the field, with the Figure overweighted relative to the ground." Our account of TSE fits in with this model of TOE, in that more attention is paid to the oddballs, which are, in effect, figures against a background of standards. Another factor suggesting that TOE is attentional in origin is the fact that the size of the TOE decreases as the ISI between the two successive stimulus presentations is increased (Allan \& Gibbon, 1994; Hellström, 1985). Although this result is difficult to explain in terms of memory trace decay or memory regression to the mean, it can be accounted for in terms of attention. As the ISI increases, the transient component of attention will decay, and less attention will be allocated to the second stimulus, diminishing the strength of the TOE. Thus, even if TSE is an example of the broad class of TOE phenomena, TOE is quite likely itself caused by differences in attentional allocation.

The predictions of counter-based theories (Creelman, 1962; Thomas \& Weaver, 1975; Treisman, 1963) and our own results can be accounted for within a simple unified model. In line with the counter-based models, durational information about an event is lost to the extent that one is not attending to that event. The processing of durational information may also get a boost when one attends to a stimulus. This could account for the temporal dynamics of the oddball-induced expansion in subjective time, reported here. Subjective time never gets "out of sync" with objective time, despite TSE, because the "rate" of subjective time per unit of objective time may be flexible, as is diagrammed in Figure 12. It may speed up when one orients to an oddball and may slow down to the extent that one is not attending to a stimulus. More than one unit of subjective time can occupy a single unit of objective time, because a unit of subjective time is a function of the amount of perceptual information pro- 

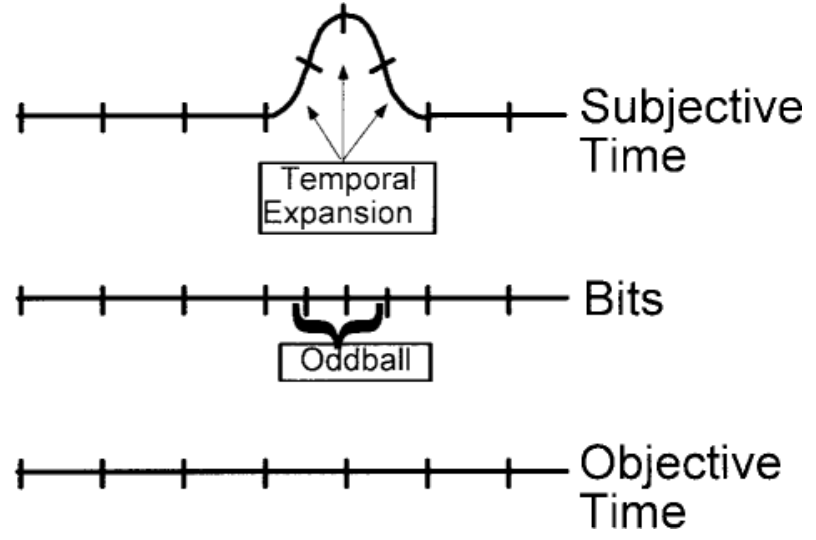

Figure 12. When an oddball occurs, more information is processed over the stimulus per unit of objective time. If subjective time is gauged in terms of the amount of perceptual information processed, subjective time will seem to expand relative to objective time, as shown at the top region indicated by "Temporal Expansion."

cessed and this amount can presumably vary per unit of objective time. An oddball stimulus would then seem to last longer than a standard stimulus of equal objective duration because it triggers an increase in perceptual information processing.

This simple model allows us to make several predictions. First, the degree of TSE should increase with the oddness, or improbability, of an oddball (as long as the oddballs are all in the temporal expansion domain-i.e., longer in duration than $\sim 150 \mathrm{msec}$, corresponding to the point where the curves cross zero in Figures 2, 3, and 6). For example, an oddball that occurs once every 10 standards should appear to last longer than an oddball that occurs once every 3 standards. A corollary of this would be that an oddball can only be so "odd," since there is presumably an upper limit on how much and how long attention can boost information-processing resources above baseline. Another prediction would be that stimuli that last longer than $\sim 150 \mathrm{msec}$ should seem to last longer when they appear in unlikely, rather than likely, locations ${ }^{3}$ contexts, or times. A related prediction is that TSE should be enhanced by more salient oddballs. Indeed, the difference between the TSE in Experiments 1 and 2 is probably due to the fact that an expanding oddball is more salient than a stationary one. Another prediction is that TSE should be able to be triggered across modalities if it is a central attentional effect. For example, an unexpected and very loud noise should make a visual stimulus appear to last longer. This raises interesting questions. When TSE occurs for a moving stimulus, it may seem to move in slow motion. Indeed, TSE may underlie the experience of slow motion during an attention-demanding event, such as skidding into the back of a car. But would TSE in the visual domain lead to an analogue of slow motion in the auditory domain? Would, for example, pitches become deeper? Or would a given pitch just seem to last longer? Because we did not check for cross-modal effects, we have not ruled out the possibility that independent visual and auditory processes, attentional or otherwise, underlie TSE in their respective domains. If these processes are independent, it may be possible to experience TSE in the auditory domain without experiencing it in the visual domain, and vice versa. For example, a sound stimulus might seem longer than sound standards, whereas a visual stimulus with simultaneous onset and offset as that sound stimulus might seem to last the same duration as its visual standards. Although such splitting of temporal expansion might seem counterintuitive, whether it occurs is an empirical question. Future research will have to address these questions. Moreover, the relationship of TSE to TOE requires clarification. If TOE is also an attentional effect, our findings on duration judgment distortions ( 150-msec onset, transient peak, sensory multimodality) should be seen along other stimulus dimensions than time, such as weight and length.

Finally, it is interesting to ask why we have evolved so as to experience events in a subjective time that can expand and, perhaps, contract relative to the presumed regular flow of objective time. One possibility is that just as attention can enhance the spatial acuity of the visual system (Mackeben \& Nakayama, 1993; Nakayama \& Mackeben, 1989; Shiu \& Pashler, 1995), attention can also enhance the temporal resolution of visual processing. Since heightened spatial or temporal resolution is presumably expensive, the visual system may invoke heightened processing only for stimuli of probable interest or importance. By making novel or important events run in slow motion they may be processed in greater depth per unit of objective time than are normal events.

\section{REFERENCES}

Allan, L. G. (1977). The time-order error in judgments of duration. Canadian Journal of Psychology, 31, 24-31.

Allan, L. G. (1979). The perception of time. Perception \& Psychophysics, 26, 340-354.

Allan, L. G. (1984). Contingent aftereffects in duration judgments. In J. Gibbon \& L. G. Allan (Eds.), Timing and time perception (Annals of the New York Academy of Sciences, Vol. 423, pp. 116-130). New York: New York Academy of Sciences.

Allan, L. G., \& Gibbon, J. (1994). A new temporal illusion or the TOE once again? Perception \& Psychophysics, 55, 227-229.

Avant, L. L., Lyman, P. J., \& AnTes, J. R. (1975). Effects of stimulus familiarity on judged visual duration. Perception \& Psychophysics, 17, 253-262.

BAYLIS, G., \& DrIVER, J. (1995). One-sided edge assignment in vision: 1 . Figure-ground segmentation and attention to objects. Current Directions in Psychological Science, 4, 140-146.

Brown, S. W. (1985). Time perception and attention: The effects of prospective versus retrospective paradigms and task demands on perceived duration. Perception \& Psychophysics, 38, 115-124.

Brown, S. W. (1995). Time, change, and motion: The effects of stimulus movement on temporal perception. Perception \& Psychophysics, 57, 105-116.

CANTOR, N. E., \& Thomas, E. A. (1977). Control of attention in the processing of temporal and spatial information in complex visual patterns. Journal of Experimental Psychology: Human Perception \& Performance, 3, 243-250.

CreElman, C. D. (1962). Human discrimination of auditory stimuli. Journal of the Acoustical Society of America, 34, 582-593. 
FECHNER, G. T. (1860). Elemente der Psychophysik. Leipzig: Breitkopf \& Härtel.

Fechner, G. T. (1882). Revision der Hauptpunkte der Psychophysik. Leipzig: Breitkopf \& Härtel.

Festinger, L., Coren, S., \& Rivers, G. (1970). The effect of attention on brightness contrast and assimilation. American Journal of Psychology, 2, 126-150.

Fraisse, P. (1963). The psychology of time. New York: Harper \& Row.

FraISSE, P. (1984). Perception and estimation of time. Annual Review of Psychology, 35, 1-36.

FrANKENHAUSER, M. (1959). Estimation of time. Uppsala, Sweden: Almqvist \& Wiksell

Garcia-Larrea, L., Lukaszewicz, A.-C., \& Mauguiere, F. (1992). Revisiting the oddball paradigm: Non-target vs. neutral stimuli and the evaluation of ERP attentional effects. Neuropsychologia, 30, 723-741.

Grondin, S., \& MaCaR, F. (1992). Dividing attention between temporal and nontemporal tasks: A performance operating characteristicPOC — analysis. In F. Macar, V. Pouthas, \& W. Friedman (Eds.), Time, action and cognition: Towards bridging the gap (pp. 119-128). Dordrecht: Kluwer.

He, Z. J., \& NaKayama, K. (1992). Surfaces versus features in visual search. Nature, 359, 231-233.

Hellström, Å. (1977). Time errors are perceptual. Psychological Research, 39, 345-388.

HELLSTRÖM, А. (1979). Time errors and differential sensation weighting. Journal of Experimental Psychology: Human Perception \& Performance, 5, 460-477.

HELlSTRÖM, A. (1985). The time-order error and its relatives: Mirrors of cognitive processes in comparing. Psychological Bulletin, 97, 3561 .

Helson, H. (1947). Adaptation level as frame of reference for prediction of psychophysical data. American Journal of Psychology, 60, 129.

Helson, H. (1964). Adaptation-level theory. New York: Harper \& Row.

Hicks, R. E., \& BRUNDIGE, R. M. (1974). Judgments of temporal duration while processing verbal and physiognomic stimuli. Acta Psychologica, 38, 447-453.

Hicks, R. E., Miller, G. W., Gaes, G., \& Bierman, K. (1977). Concurrent processing demands and the experience of time-in-passing. American Journal of Psychology, 90, 431-446.

Hicks, R. E., Miller, G. W., \& Kinsbourne, M. (1976). Prospective and retrospective judgments of time as a function of amount of information processed. American Journal of Psychology, 89, 719-730.

Hikosaka, O., Miyauchi, S., \& Shimojo, S. (1993). Focal visual attention produces illusory temporal order and motion sensation. $\mathrm{Vi}$ sion Research, 33, 1219-1240.

HOLLINGWORTH, H. L. (1910). The central tendency of judgment. Journal of Philosophy, Psychology, \& Scientific Methods, 7, 461-468.

HüLSER, C. (1924). Zeitauffassung und Zeitschätzung verschieden ausgefüllter Intervalle unter besonderer Berücksichtigung der Aufmerksamkeitsablenkung. Archiv der Gesamten Psychologie, 49, 363-378.

Irwin, D. E., Colcombe, A. M., Kramer, A. F., \& Hahn, S. (2000). Attentional and oculomotor capture by onset, luminance and color singletons. Vision Research, 40, 1443-1458.

JAMES, W. (1950). The principles of psychology. New York: Dover. (Original work published 1890)

Jamieson, D. G., \& Petrusic, W. M. (1975). Pairing effects and timeorder errors in duration discrimination. Perception \& Psychophysics, 18, 107-113.

JoNIDES, J., \& YANTIS, S. (1988). Uniqueness of abrupt visual onset in capturing attention. Perception \& Psychophysics, 43, 346-354.

Kahneman, D. (1973). Attention and effort. Englewood Cliffs, NJ: Prentice-Hall.

Katz, D. (1906). Experimentelle Beiträge zur Psychologie des Vergleichs im Gebiete des Zeitsinns [Experimental contributions to the psychology of our sense of time]. Zeitschrift für Psychologie, Physiologie der Sinnesorgane, 42, 302-340.

LeubA, A. (1892). A new instrument for Weber's law; with indications of a law of sense memory. American Journal of Psychology, 5, 370-384.

Macar, F., Grondin, S., \& Casini, L. (1994). Controlled attention sharing influences time estimation. Memory \& Cognition, 22, 673686.
Mackeben, M., \& Nakayama, K. (1993). Express attentional shifts. Vision Research, 33, 85-90.

MATTES, S., \& ULRICH, R. (1998). Directed attention prolongs the perceived duration of a brief stimulus. Perception \& Psychophysics, $\underline{\mathbf{6 0}}_{2}$ 1305-1317.

McKee, S. P., Klein, S. A., \& Teller, D. Y. (1985). Statistical properties of forced-choice psychometric functions: Implications of probit analysis. Perception \& Psychophysics, 37, 286-298.

Michon, J. A. (1978). The making of the present: A tutorial review. In J. Requin (Ed.), Attention and performance VII (pp. 89-109). Hillsdale, NJ: Erlbaum.

Nakajima, Y., ten Hoopen, G., Hilkhuysen, G., \& Sasaki, T. (1992). Time-shrinking: A discontinuity in the perception of auditory temporal patterns. Perception \& Psychophysics, 51, 504-507.

NAKaJima, Y., TEN HoOPEN, G., \& VAN DER WILK, R. G. H. (1991). A new illusion of time perception. Music Perception, 8, 431-448.

NaKayama, K., \& Mackeben, M. (1989). Sustained and transient components of focal visual attention. Vision Research, 29, 1631-1647. ORNSTEIN, R. E. (1969). On the experience of time. Baltimore: Penguin. Petrusic, W. M. (1984). Explicit counting and time-order errors in duration discrimination. In J. Gibbon \& L. Allan (Eds.), Timing and time perception (Annals of the New York Academy of Sciences, Vol. 423, pp. 630-633). New York: New York Academy of Sciences.

Polich, J. (1986). Attention, probability, and task demands as determinants of P300 latency from auditory stimuli. Electroencephalography\& Clinical Neurophysiology, 63, 251-259.

Potts, G. F., Liotti, M., Tucker, D. M., \& Posner, M. I. (1996). Frontal and inferior temporal cortical activity in visual target detection: Evidence from high spatially sampled event-related potentials. Brain Topography, 9, 3-14.

Pratt, C. C. (1933). Time-errors in the method of single stimuli. Journal of Experimental Psychology, 16, 798-814.

Predebon, J. (1996). The relationship between the number of presented stimuli and prospective duration estimates: The effect of concurrent task activity. Psychonomic Bulletin \& Review, 3, 376-379.

QuASEBARTH, K. (1924). Zeitschätzung und Zeitauffassung optisch und akustisch ausgefüllter Intervalle. Archiv der Gesamten Psychologie, 49, 379-432.

Remington, R. W., Johnston, J. C., \& Yantis, S. (1992). Involuntary attentional capture by abrupt onsets. Perception \& Psychophysics, $\underline{\mathbf{5 1}}_{2}$ 279-290.

RENSINK, R. A., \& ENNS, J. T. (1995). Preemption effects in visual search: Evidence for low-level grouping. Psychological Review, 102, 101-130.

Rose, D., \& Summers, J. (1995). Duration illusions in a train of visual stimuli. Perception, 24, 1177-1187.

SCHAB, F. R., \& CROWDER, R. G. (1988). The role of succession in temporal cognition: Is the time-order error a recency effect of memory? Perception \& Psychophysics, 44, 233-242.

SchiffMAN, H. R., \& BoBKo, D. J. (1974). Effects of stimulus complexity on the perception of brief temporal intervals. Journal of Experimental Psychology, 103, 156-159.

SHIU, L.-P., \& PASHLER, H. (1995). Spatial attention and vernier acuity. Vision Research, 35, 337-343.

Stelmach, L. B., Herdman, C. M., \& McNeil, K. R. (1994). Attentional modulation of visual processes in motion perception. Journal of Experimental Psychology: Human Perception \& Performance, $\underline{\mathbf{2 0}}_{2}$ 108-121.

Thomas, E. A. C., \& Brown, T. I., JR. (1974). Time perception and the filled-duration illusion. Perception \& Psychophysics, 16, 449-458.

Thomas, E. A. C., \& Cantor, N. E. (1978). Interdependence between the processing of temporal and non-temporal information. In J. Requin (Ed.), Attention and performance VII (pp. 43-62). Hillsdale, NJ: Erlbaum.

Thomas, E. A. C., \& Weaver, W. B. (1975). Cognitive processing and time perception. Perception \& Psychophysics, 17, 363-367.

Treisman, M. (1963). Temporal discrimination and the indifference interval: Implications for a model of the "internal clock." Psychological Monographs, 77, 1-31.

Tse, P. U., Sheinberg, D. L., \& Logothetis, N. K. (2003). Attentional enhancement opposite a peripheral flash revealed using change blindness. Psychological Science, 14, 91-99. 
Underwood, G., \& SwaIn, R. A. (1973). Selectivity of attention and the perception of duration. Perception, 2, 101-105.

VIERoRdT, K. von (1868). Der Zeitsinn nach Versuchen. Tübingen: Laupp.

WeINBERG, L. (1991-1995). Poser [Computer software]. Fractal Design Corp.

Woodrow, H. (1930). The reproduction of temporal intervals. Journal of Experimental Psychology, 13, 473-499.

Woodrow, H. (1951). Time perception. In S. S. Stevens (Ed.), Handbook of experimental psychology (pp. 1224-1236). New York: Wiley.

YANTIS, S., \& EgETH, H. E. (1999). On the distinction between visual salience and stimulus-driven attentional capture. Journal of Experimental Psychology: Human Perception \& Performance, 25, 661-676.

YANTIS, S., \& JONIDES, J. (1990). Abrupt visual onsets and selective attention: Voluntary versus automatic allocation. Journal of Experimental Psychology: Human Perception \& Performance, 16, 121-134.

ZAKAY, D. (1993). Time estimation methods: Do they influence prospective duration estimates? Perception, 22, 91-101.

ZAKAY, D., \& TsaL, Y. (1989). Awareness of attention allocation and time estimation accuracy. Bulletin of the Psychonomic Society, 27, 209-210.

\section{NOTES}

1. In the literature on duration perception, the terms unit, cue, and pulses are used equivalently in the context of clock/counter models.
2. An increased rate of information processing might favor an early view of attentional action, where, for example, sensory neurons actually increase their rate of firing when acted upon by neuronal circuitry that realizes attentional allocation. Conversely, increased sensitivity, but a constant information-processing rate, might predict that early neurons whose receptive fields lie within an attended region would not demonstrate a rate of firing above nonattended baseline. Of course, increased sensitivity in the form of a lowered firing threshold would tend to make a neuron fire more than when threshold was not lowered, suggesting that the mechanism that increases sensitivity to processed information could be inextricably linked to the mechanism that increases the rate of information processed.

3. In a very different paradigm from our own, Stelmach, Herdman, and McNeil (1994) found that stimuli appear to last longer when they appear in unexpected, rather than expected, locations. Mattes and U1rich (1998), however, found the opposite to be true. This discrepancy may be due to the differing nature of the experimental paradigms used. In our task, endogenous (sustained, willed) and exogenous (transient) attentions were not in competition, because both were allocated to the same location. When an oddball appeared in the center of the screen, transient attentional resources could be allocated in addition to any sustained component that was already allocated at that position. In the Posner cuing kinds of tasks used by Mattes and Ulrich, endogenous and exogenous components would have been in conflict. This may have mitigated any TSE due to the transient component alone. Moreover, Mattes and Ulrich tended to test cues at very short durations and may not have entered the temporal expansion domain because of this.

(Manuscript received June 28, 2001;

revision accepted for publication January 29, 2004.) 